\title{
Generalization of the Thermal Dose of Hyperthermia in Oncology
}

\author{
Gyula Vincze, Oliver Szasz, Andras Szasz* \\ Szent István University, Gödöllő, Hungary \\ Email: ${ }^{*}$ Szasz.Andras@gek.szie.hu
}

Received 3 July 2015; accepted 25 October 2015; published 28 October 2015

Copyright (C) 2015 by authors and Scientific Research Publishing Inc.

This work is licensed under the Creative Commons Attribution International License (CC BY). http://creativecommons.org/licenses/by/4.0/

c) (i) Open Access

\begin{abstract}
Hyperthermia has been a modality to treat cancer for thousands of years. During this time, intensive efforts are concentrated on determining the dose of the proper treatment, but the dominantly in vitro induced cellular death does not provide enough confidence for the clinical dosing. The cell-death by heat-monotherapy applications in laboratory experiments is difficult to apply in the complementary therapies in clinical applications. The newly developed nanotechnologies offer completely new possibilities in this field as well. Modulated electro-hyperthermia (mEHT, tradename Oncothermia) is a nanoheating technology that has selective effects on membrane rafts and on the transmembrane proteins. This effect is thermal. The thermal action is in nanoscopic range which makes the phenomenon special. Our objective is to show the dose concept on this emerging method.
\end{abstract}

\section{Keywords}

Thermal Dose, Oncothermia, Nano-Targeting

\section{Introduction}

Hyperthermia, as a treatment in oncology, has a thousand-year tradition [1]. It has tremendous fluctuations in its applications and trusts in its efficacy [2]. This addresses serious questions: "Where are we?" [3], "Where are we going?” [4]. One of the central problems of the hyperthermia in oncology is the dosing [5]. The problem of the dose is very general due to that the temperature is the central parameter of this heating method. However, the focusing of the energy-absorption doesn't mean the focus of the temperature too, because the heat spread by time is forced mainly by a very effective heat-exchanger: the blood-flow. Our objective in this paper is to clarify the dosing which is based on the in vitro experiments of necrotic distortion fitting it to the Arrhenius plot. We

${ }^{*}$ Corresponding author. 
generalize this Arrhenius based on dosing, including the direct SAR, from the selectively targeting electric field.

Oncologic hyperthermia massively uses external heat transfer from the outside towards the inside. The classical solution is based on heat-conduction from the skin. The heat-conduction is robustly increased by heatconvection of the induced intensive blood-flow in the skin.

The whole-body heating processes definitely follow this way, using the blood-flow in the subcutaneous capillary-bed, transferring the absorbed energy all over the body [6]. The method has many early descriptions [7][10]; but the dominant systemic hyperthermia method is based on the infra-red radiation by multi-reflecting filtering [11] [12] or by water-filtering [13] [14].

Another type of oncological hyperthermia is not systemic. Its volume ranges widely: from regional to local, from a part of the body to a nanoscopic targeting.

Their typical parameters are summarized in Table 1.

Thermodynamically, the systemic and loco-regional treatments differ from their heat-flow direction between the tumor and its neighborhood. The blood-heating techniques pump heat-energy from blood to the tumor, while the blood works opposite in the loco-regional heating, cooling the anyway heated tumor because it remains in body temperature. The physiological limits are also different. While the systemic heating is limited at $42^{\circ} \mathrm{C}$, the local one has no limit in the tumor. The temperature limit of loco-regional treatment is only keeping the healthy vicinity of the tumor safe, as well as the skin, where the energy is pumped into the body.

Technically, the local deep-focusing is a great challenge. Most of the local treatments with deep focusing possibility use some kind of electromagnetic energy-absorption. Multiple new techniques are devoted to deliver the proper energy for heating [15].

One of the earliest non-invasive deep heating is the simple inductive way, which is typically achieved by the induction of eddy-currents in the body [16]-[18]. This method has low efficacy, but its non-invasive penetration easily crosses over the body, and its focusing or selective orienting is not possible. Other loco-regional electromagnetic heating methods work by radiative [19]-[21], or by capacitive [22]-[24], technical solutions. These non-invasive electromagnetic heating solutions use a wide range of frequencies, having definitely different effects and penetration depth to the body [14]. However, in most of the cases, the limited penetration depth is enough for effective deep heating [25].

Interestingly, the trend of the modern hyperthermia is directed to the smaller targets. Their intensive locality is somehow similar in this character to the original galvanic methods. The typical high-energy focusing can be solved by microwaves [26] or very locally by interstitial heating invasively [27]. It delivers heat to the tumor mass directly using a needle providing high frequency. Typically, this type of therapy is applied in an image guided way. These ablation methods work by typical burn-necrosis basis, and the energy is typically provided by impedance-heating with minimally invasive electrode insertion; there is no heat-flow through the skin. Some typical applications are for liver [28], lung [29] [30], and breast [31]. Numerous ablative, interstitial hyperthermia combined with local irradiation are applied for brain tumors [32]-[35], and implant applications [36] [37], and also combined with laser techniques [38] [39].

Some modern laser ablative techniques work with ultrafast pulses with ultra large energy-density flow. Depending on the pulse-duration, it can be a few $100 \mathrm{~W} / \mathrm{cm}^{2}$ and in nano-seconds can go to $10^{7}-10^{8} \mathrm{~W} / \mathrm{cm}^{2}$ [40], but the provided energy altogether reaches its maximum at a few tenths of watts. Their application for liver [41], [42], is common. This emerging technology, together with the electroporation techniques, has been shifted more-and-more to become the tool of surgery, applied it on intraoperative way, or applied by interventional radiology, isolated a little bit from the general hyperthermia practices.

The photodynamic therapy (PDT) [43], uses heating of the micro-targets like photosensitized liposomes or other photosensitizers [44], by infrared or visible radiation. The micro-absorption of the heat assists targeted

Table 1. Typical physical parameters of the basic hyperthermia-treatment categories.

\begin{tabular}{cccc}
\hline $\begin{array}{c}\text { Basic hyperthermia } \\
\text { categories }\end{array}$ & $\begin{array}{c}\text { Typical absorbed energy density } \\
\text { (SAR) }[\mathrm{W} / \mathrm{kg}]\end{array}$ & $\begin{array}{c}\text { Typical operating } \\
\text { temperature }\left[{ }^{\circ} \mathrm{C}\right]\end{array}$ & $\begin{array}{c}\text { Typical treated mass }[\mathrm{kg}] \\
\text { Systemic (blood-heating) }\end{array}$ \\
$5 \div 10$ & $38 \div 42$ & $40 \div 100$ \\
Local/regional (tissue heating) & $10 \div 50$ & $40 \div 45$ & $1 \div 25$ \\
Ablation (tissue burning) & $5000 \div 25,000$ & $60 \div 250$ & $0.001 \div 0.02$ \\
\hline
\end{tabular}


drug-delivery, combined with the heat development. This could non-invasively treat shallow-seated tumors, only the light-source has to be introduced invasively (mostly with optical fibers) for heating in depth.

There is a selective tumor targeting applied by temperature sensitive liposome-jacketed drug-delivery [45], as well as the drug delivery with temperature activated nanoparticle complexes [46]. PDT can be applied with nanoparticle administration too [47], when the particles are the real absorbers of the energy. The method is based on artificially set nanoparticle concentration in the targeted volume [48] [49].

The disadvantage of the weak coupling of magnetic fields in direct inductive heating turns to an advantage when artificial absorbers are applied. The energy absorption from the magnetic field is practically limited to these magnetic absorbing centers, orienting the SAR where the artificially inserted magnetic materials are. These materials will solely react with the electromagnetic fields, and their absorbed energy will be the source to heat up their surroundings. The energy absorption could be absolute, precisely guided by the place of these absorbers. In order to improve the magnetic energy absorption within the target tissue, magnetic materials, such as micro-particles [50] and ferrite rods [51], are usually injected into the targeted area [52], orienting the field to the particles and massively absorbing the incident energy. The emerging application of magnetic treatments is started by the nanoparticle magnetic suspensions [53] and other magnetic liquids.

Definite shifts of hyperthermia techniques have been made in the last decade, showing a trend to nanotechnology [54]. Applications of various nanoparticles for combined hyperthermia are new, emerging methods in oncology [46]. In this method the nanoparticles (which are usually administered in a suspension [53]) are small heat-absorbers. They are selectively heated up by an outside photo-energy or magnetic field [55], which acts exclusively only on these nanoparticles. The trick here is the accurate targeting of the heat-absorption. The overheated nanoparticles soon give their heat-energy to their neighborhood and heatup the complete lesion in their vicinity. A great deal of energy is pumped into these nanoparticles being able to heatup the complete mass, containing a large amount of electrolytes. However, most of the electrolytes are uselessly heated up because the heat has to be concentrated on the tumor cells and exclusively on their membranes to damage them. This request needs a higher preciosity addressing the nanoparticles selectively on the surface of the tumor cells, which can be made by antibody-nanoparticle conjugates [56]. It releases the therapeutic targets at the connected malignant cells while minimizing off-target side effects. When the delivering nanoparticle - which is especially bonded to the membrane of the malignant cell—is heated up by an outside field, it could have a double effect: damaging the membrane by heat and/or release the drug that was delivered to the target [57]. Most of the nanoparticle hyperthermia effects are subcellular, inducing intracellular action [58]; however, the efficacy of this treatment is debated [59].

Based on nanotechnology, a new, emerging way is connected to various immune actions [60], which could be applied in loco-regional hyperthermia, too. This transforms the modern local hyperthermia treatment completely systemic [61] [62], reaching bystander and abscopal effects [63] [64], by production of the immune-stimulating character for both the innate and adaptive immune system [65], and turning the oncologic hyperthermia to a complex immune-therapy, attacking the far-distant metastases, named "immunotherm" therapy [66].

\section{Dosing of Hyperthermia}

Evaluating the success of hyperthermia's definitive dose is mandatory. Experts agree that the reliable dosing determines the future of oncologic hyperthermia [66].

The heating process is an energy transfer to the target. This energy could increase the temperature and could make many other accompanied effects [67] [68]. Naturally, the medical expectation is definitely making changes in the target, killing the malignant cells in various ways. The cell killing obviously demand senergy, which is delivered by the electromagnetic or mechanical (ultrasound) forms in most of the hyperthermia methods. The temperature is the average energy that is provided to the target. When the target is large, it needs more heatenergy to reach the same temperature than the small target. This is why we introduced the absorbed energy for unit volume or unit mass, as we did in case of ionizing radiation: $\mathrm{J} / \mathrm{kg}(=\mathrm{Gy})$. This is an exact dose that we can use when we know the absorbed energy. However, the target is not isolated thermally, so it loses a lot of heatenergy by heat-conduction to the neighbors, and by the intensive heat exchange of the blood-flow. Also, the problematic point is the energy-delivery path. The energy is transported through the non-targeted volumes from the surface to the target, losing a large amount of the energy out of the target. This is not only wasted energy, but also a source of the thermal toxicity. The surface cooling makes the next complication, which sinks a lot of for- 
warded energy to the cooler. These points request a local measurement in the target. What to measure? We could measure the absorbed energy; or easier to measure, the temperature there, which we suppose has monotonic calibration to the energy itself. So the temperature has a role of some kind of dosing by calibration to absorbed energy; also, it is a safety parameter with the help of which we can be sure that the target does not have too toxic energy-exposition for the healthy tissue.

When the energy-absorption and the energy-distribution is heterogenic, and has fluctuations in the volume, then the temperature measurement also has fluctuations, and we have to wait while the temperature is "equalized" to become a steady-state condition, where the temperature can be regarded as constant. This process emphasizes the time-parameter as important as the temperature itself in two ways: 1) Time duration and energy delivery are linearly proportional; 2) Longer time spreads the energy, approaches equilibrium mostly by non-linear way. Taking into consideration these parameters, complications grow with the heterogeneity of the absorbing target. For example, in case of the nanoheating an extremely huge energy density is absorbed in a very small volume, and the main heating effect is based on their heat-conductive environment.

For the proper dose definition, a well-defined goal (the expected effect) has to be described. The dose in this case must be derived from various model systems (in silico, in vitro and in vivo), while clinicians apply this method at the patient's bed. Unfortunately, the two approaches (experimental and medical) do not meet organically. One of the multiple reasons of deviations is that the model systems are mostly treated by monotherapies, while medical practice predominantly uses the oncologic hyperthermia as a complementary method together with one or more "gold standards". On the other hand, the biological variability is much more in the real treatment on humans than in the models. During experimental trials we can investigate the basic (mainly molecular) mechanisms of hyperthermia, while the clinical applications are sharply connected to the various physiological reactions, like the blood-flow, lymph-transports, and in consequence, the drug-delivery of chemotherapies, the oxygenation for radio-sensitizing, etc. Some special functional parameters of the treated organ are used for control of the in situ actions, but these methods are not at all standard enough to be used for dosing. The control of this type gives important safety information to avoid or minimize the adverse reactions, but not appropriate to use as dose. Some technical, mainly thermal parameters are also used to control the processes without proper dose. For example, the highest temperature achieved is used [69], or the total heat-energy is counted [70], or the time of exposure is chosen for characterization [71]. These methods are technically precise, but they are not enough to characterize the biological response. While dosing we have to consider the complex physiological response of the target, which drastically modifies the absorbed energy and the temperature.

The concept of oncological doses is based on the maximal tolerable dose determined by dose escalation, measured in specific concentration of the drug (such as $\mathrm{mg} / \mathrm{m}^{2}$ ), or specific energy of the radiation (such as $\mathrm{Gy}=$ $\mathrm{J} / \mathrm{kg}$ ). The efficacy is measured mostly by the local control, the response rate, which is measured most frequently off-situ with imaging techniques. When the efficacy is measured on the survival or other long-time realization of the development of the disease (much longer than the treatment is active), it would be too complex to verify it as the dose, due to the fact that the interim control during the treatment process is mandatory.

The definition of the real dose must be based on the effect, which we expect by the application of the proper dose. The dose of an action is measured by the final effect, which is made by a "tool" (such as drug concentration, radiation, temperature, etc.). The effect in our case is the selective distortion of the cancer cells. The definition of the distortion is the cell-death of malignant cells without harm (or less harm) in their healthy counterpart. There are various possible ways of cell-killing in a wide range from necrosis to apoptosis, or autophagy, having many variations of their "mixture", called necroptosis, aptonecrosis, etc. [72]. These processes could happen on avery different time-scale, depending on their regulatory pathways; and the necrotic cell-death could be complexly regulated [73].

The inherent problem of dosing is that the quantity of the final result of the action of the tool is defined by the tool itself (concentration, intensity, etc.). The way from the action to the result considered standard is too rough—an oversimplified assumption in high complexity systems with high bio-variability.

The majority of physicians who are using heating techniques have a common view about the cellular damage, stating its thermal behavior. However, the same forwarded energy exposition with identical energy-flow $\left[\mathrm{W} / \mathrm{m}^{2}\right]$ can cause different energy-absorptions [74] depending on the given conditions [75] [76], the actual organ [77], and also modified by the actual frequency [78].

The simplest thermodynamical way is of course to measure the temperature, and by the higher kinetic energy that surmounts the energy barrier of the actual reactions. However, the heating differs in the target, even micro- 
scopically, and the same temperature acts differently for the large complex chemical machinery of the cell. If the temperature is high enough it acts for most of the possible reactions, irrespective of their state or actual needs. Due to the overall excitations the desired selection vanishes. Energizing by temperature does not take into account the individual energy barriers of the various reactions or reaction cascades; it is an overall driving force to react. It defines a certain probability of the effect of individual reactants. When the given reaction has the $E_{a}$ barrier height (activation energy), the reaction rate $k$ (probability of overpassing the barrier) is proportional to the exponential function of the ratio of the height of the barrier and the energy represented by the temperature that can be described by the Arrhenius law

$$
k=A \exp \left(-\frac{E_{a}}{R_{G} T}\right)
$$

where $R_{G}$ is a universal gas-constant $\left(R_{G} \approx 8.3[\mathrm{~J} / \mathrm{K} / \mathrm{mol}]\right)$. The excitation of the particles is temperature dependent. The actual pre-exponential factor $(A)$ and the $E_{a}$ activation energy have to be determined on an experimental basis. The general basis of the chemical reaction-kinetics with temperature is the Arrhenius law. The ATP synthesis is temperature dependent, also following the Arrhenius law [79].

\section{Sapareto-Dewey's Approximation of Dose of Thermal Damage}

The theoretical model of the criteria of the cell-death is described by the

$$
N \stackrel{\chi}{\longrightarrow} D
$$

simple reaction equation, which means the living cell $N$ turns to (number of) dead one $D$ by reaction rate $\chi$. This could be modelled by autolysis, having the linear decay equation

$$
\frac{\mathrm{d} C(t)}{\mathrm{d} t}=-\chi C(t)
$$

where $C(t)$ is the concentration of the living cells in $t$-time. The $\chi$ reaction rate could be given by the Arrhenius Equation (1), so

$$
\chi=\alpha \mathrm{e}^{-\frac{E_{a}}{R_{G} T}}
$$

The thermo-dynamical measurement of necrotic hyperthermia treatments in-vitro accurately fits the Arrhenius plot [80] [81]. The relevant reaction rate could be calculated from the slope of the survival rate by treatment time.

Introducing the damage function

$$
\Omega(t)=\ln \left(\frac{C(0)}{C(t)}\right)
$$

It follows

$$
\frac{\mathrm{d} \Omega(t)}{\mathrm{d} t}=\alpha \mathrm{e}^{-\frac{E_{c}}{R_{G} T}}
$$

Knowing the relevant parameters, the thermal dose is calculable from this equation [82], as

$$
\Omega(t)=\int_{0}^{t} \alpha \mathrm{e}^{-\frac{E_{c}}{R_{G} T(\tau)}} \mathrm{d} \tau
$$

When the chemical or structural properties change, the value of $E_{c}$ changes, too. Due to the linearity of the Arrhenius plot and its reverse time dimension of $\chi$, we introduce its reciprocal value as time constant [83] as $\Theta=1 / \chi$. When we have the ratio of two different time-constants as $\Theta\left(T_{1}\right) / \Theta\left(T_{2}\right)$ where $T_{1}$ and $T_{2}$ are close to each other, then

$$
\frac{\Theta\left(T_{2}\right)}{\Theta\left(T_{1}\right)}=\mathrm{e}^{-\frac{E_{a}}{R_{G} T_{1} T_{2}}\left(T_{2}-T_{1}\right)}=\left(\mathrm{e}^{-\frac{E_{a}}{R_{G} T_{1} T_{2}}}\right)^{\left(T_{2}-T_{1}\right)} \cong \Psi^{\left(T_{2}-T_{1}\right)}=\frac{\Psi^{T_{2}}}{\Psi^{T_{1}}} \quad\left\{\Psi=\mathrm{e}^{-\frac{E_{a}}{R_{G} T_{1} T_{2}}}\right\}
$$


The thermal damage has a characteristic graph in dependence of $1 / T$ as usually plotted by the Arrhenius conditions

$$
\frac{1}{\Theta}=\alpha \mathrm{e}^{-\frac{E_{a}}{R_{G} T}} \rightarrow \ln \left(\frac{1}{\Theta}\right)=\ln \alpha-\frac{E_{a}}{R_{G}} \frac{1}{T}
$$

In case of components of living materials (like proteins, cells, tissues) the $\ln (A)$ is approximated from the experiments by linear dependence

$$
\ln \alpha=\xi E_{a}+\zeta
$$

where $\xi=0.38$ and $\zeta=-9.36$ [84], or in other publication $\xi=3.832$ and $\zeta=10.042$ [84] [85].

So the characteristic time is

$$
\ln (\Theta)=\left(\frac{1}{R_{G} T}-\xi\right) E_{a}-\zeta
$$

Comparing the thermal cell damages to each other, we choose treatments made on $T_{1}$ temperature by $t_{1}$, time and other one on $T_{2}$ temperature by $t_{2}$ duration. According to Equation (7) the thermal damage functions are

$$
\begin{aligned}
& \Omega_{t}\left(t_{1}, T_{1}\right)=\alpha \mathrm{e}^{-\frac{E_{a}}{R_{G} T_{1}}} t_{1}=\frac{t_{1}}{\Theta\left(T_{1}\right)} \\
& \Omega_{t}\left(t_{2}, T_{2}\right)=\alpha \mathrm{e}^{-\frac{E_{a}}{R_{G} T_{2}}} t_{2}=\frac{t_{2}}{\Theta\left(T_{2}\right)}
\end{aligned}
$$

We consider two treatments thermally equal, when their thermal damages are equal. We can choose equivalent times using Equation (12), when we would like to compare the effects of $t_{1}-T_{1}$ and $t_{2}-T_{2}$ time-temperature pairs. Consequently, with the approximation in Equation (8), we get

$$
\frac{t_{1}}{\Theta\left(T_{1}\right)}=\frac{t_{2}}{\Theta\left(T_{2}\right)} \rightarrow t_{2}=t_{1} \frac{\Theta\left(T_{2}\right)}{\Theta\left(T_{1}\right)}=t_{1} \Psi^{T_{2}-T_{1}}
$$

If the reference-time and corresponding temperatures are $t_{r}$ and $T_{r}$ respectively, then the iso-effective equivalent time, which is necessary at the $T$-temperature would be

$$
t=\frac{t_{r}}{\Theta\left(T_{r}\right)} \Theta(T)=t_{r} \Psi^{T_{r}-T} \quad\left\{\Psi=\mathrm{e}^{-\frac{E_{a}}{R_{G} T_{r} T}} \approx \mathrm{e}^{-\frac{E_{a}}{R_{G} T_{r}^{2}}}\right\}
$$

When we choose $t_{2}=t_{r}$ as reference time at temperature $T_{2}=T_{r}$, we get a simple equation for isodose with $t_{r}-T_{r}$ pair when we use $t-T$ in actual treatment, according to Equation (13)

$$
t=t_{r} \Psi^{T-T_{r}}=Q \Psi^{\frac{\Delta T}{T_{r}}} \text { where } Q=t_{r} \Psi^{T_{r}} \cong \text { const. }
$$

where $\Delta T=T-T_{r}$. In this way, the equivalent time depends on the relative temperature difference by a power-law

$$
\ln (t)=\ln (Q)+\left(\frac{\Delta T}{T_{r}}\right) \ln (\Psi)
$$

In consequence of this $t_{r}$ reference choice, we can introduce a dose unit; when the heating is time-dependent, summarizing all the intervals regarded as constant temperature, using steady-state approximation. This cumulative value as "cumulative equivalent minutes" (CEM) is in steady-state

$$
\mathrm{CEM}=\sum_{i=0}^{n} t_{i} \Psi^{T_{r}-T\left(t_{i}\right)}
$$

where $t_{i}$ are the times when the corresponding $T\left(t_{i}\right)$ regarded as constant. In a continuous change of the temperature, the sum is transformed to an integral 


$$
\mathrm{CEM}=\int_{0}^{t} \mathrm{~d} \tau \Psi^{T_{r}-T(\tau)}=Q \int_{0}^{t} \mathrm{~d} \tau \Psi^{\frac{\Delta T(\tau)}{T_{r}}}
$$

where the treatment time $t$ is conventionally measured in minutes. The general equivalent time CEM in Equation (18) does not fix the reference for one definite cell-death, it is general for all the cases when the Arrhenius process is valid.

When the activation energy is constant, the Arrhenius plot is linear by the reciprocal of the temperature. However, when a drastic new reaction or phase transition happens the activation energy changes and the derivative of the Arrhenius curve is modified by the thermal load with increasing temperature. In this case, the anyway linear dependence of the logarithm of reaction-rate to 1/T breaks, the slope of the line changes, and a kink occurs on the Arrhenius plot [83]. When the transition is irreversible, the modified activation energy remains characteristic in the temperatures, when the curve had another derivative anyway, establishing the basic of the step-down heating [80]. In consequence of the kinked sequentially linear dependence the temperature of the time-constant could also be easily plotted [83]. When one of the conditions of the $273 \& T_{2}-273 \geq T_{k}$ or $T_{1}-273 \&$ $T_{2}-273<T_{k}$, [where $T_{k}$ is the temperature (in Celsius units) $T_{1}$-where the kink ( $E_{a 1} \leftrightarrow E_{a 2}$ transition) occurs] relations are valid, we have

$$
\Psi=\left\{\begin{array}{ll}
\mathrm{e}^{-\frac{E_{a 1}}{R_{G} T_{1} T_{2}}} & \text { if } T \geq T_{k} \\
\mathrm{e}^{-\frac{E_{a 2}}{R_{G} T_{1} T_{2}}} & \text { if } T<T_{k}
\end{array}= \begin{cases}\Psi_{1} & \text { if } T \geq T_{k} \\
\Psi_{2} & \text { if } T<T_{k}\end{cases}\right.
$$

The step-function form of $\Psi$ is consequence of the kink measured in the Arrhenius plot at temperature $T_{k}$, [K]. Classic hyperthermia had chosen for standardization this $t_{43}$ point. Conventionally, the value of $\Psi$ is noted $R$ in this special necrosis-based standardization. By this choice, the reference point was definitely fixed as the necrotic threshold in the special in vitro experiments [86]. In most cases of thermal necrotic cell-death, approved mostly in in vitro experiments $T_{k}=316 \mathrm{~K}=43^{\circ} \mathrm{C}$ and $\Psi_{1}=0.5, \Psi_{2}=0.25$ [80], showing there is as large reduction as almost $1 / 3$ of the activation-energy above this point [87] ( $\Psi$ denoted with $R$ in this special case). The in vivo model-experiments are near to this breaking point [88], due to the fact that it is connected to a lipid-phase transition in a cell membrane. The reference values are connected tonecrosisat $T_{2}=43^{\circ} \mathrm{C}$, made during a treatment-time $t_{43}$. The dose of the actual treatment refers on the equivalent time of the treatment on other $T$ temperature (denoted by $\mathrm{CEM} 43^{\circ} \mathrm{C}$ ) [89]. It could be calculated as

$$
\begin{aligned}
& \text { CEM43 }{ }^{\circ} \mathrm{C}=\int_{0}^{t} \mathrm{~d} \tau R^{43-T(\tau)} \\
& R= \begin{cases}0.5 & \text { if } T \geq 43^{\circ} \mathrm{C} \\
0.25 & \text { if } T<43^{\circ} \mathrm{C}\end{cases}
\end{aligned}
$$

which implies $E_{a\left(<43^{\circ} \mathrm{C}\right)}=273 \mathrm{kcal} / \mathrm{mol}$ and $E_{a\left(\geq 43^{\circ} \mathrm{C}\right)}=138 \mathrm{kcal} / \mathrm{mol}$. The kink temperature of the Arrhenius plot could vary by samples, and complementary or pre-treatments [90]. The most likely effect causing the kink is well to the believed lipid phase transition observed around $42.5^{\circ} \mathrm{C}$ [83], but other effects modifying other essential proteins are also possible. The choice of the $43^{\circ} \mathrm{C}$ for the breakpoint was supported by the value of the blood-flow contraction threshold, which is at about $42.5^{\circ} \mathrm{C}$ [91], and also, it corresponds.

However, according to the various experiments below and above the breakpoint temperature, the activation energies do not fit to the fixed $R$ values. One well-accepted result [92] shows $E_{a 1}=365 \mathrm{kcal} / \mathrm{mol} \approx 1527 \mathrm{~kJ} / \mathrm{mol}$ below this point, while above $E_{a 2}=148 \mathrm{kcal} / \mathrm{mol} \approx 620 \mathrm{~kJ} / \mathrm{mol}$. These values implicate $R_{\left(<43^{\circ} \mathrm{C}\right)}=0.159 ; R_{\left(\geq 43^{\circ} \mathrm{C}\right)}=$ 0.474 , instead of $R_{\left(<43^{\circ} \mathrm{C}\right)}=0.25 ; R_{\left(\geq 43^{\circ} \mathrm{C}\right)}=0.5$, respectively. The error is significantly robust $(\sim 36 \%)$, below the breakpoint, showing that the non-necrotic damage cannot be described accurately with the classic $\mathrm{CEM} 43^{\circ} \mathrm{C}$ dose.

\section{Generalized Dose}

The Arrhenius picture is useful for various heating induced changes in tissues and in physiological phenomena [86]. The measured parameters in these biologically quite high temperatures are remarkably higher than those of 
the simple chemical processes.

The cell-death could be performed by various parallel ways. Keeping the standard Arrhenius-based Henrique-Moritz model [93], we assume that all the cell-damages are necrotic, and could be modelled by parallel, dominantly irreversible chemical reactions. However, there is a robust cellular reparation mechanism, which blocks the cell-death in part of the cells. These cells are able to recover their damaged proteins by reparation (mainly HSP chaperones are active in this effect), and survive the thermo-electro attack. Even a part of these cells could become heat-resistant [94].

There are various kinds of the cell-deaths, having a huge variation of the activation energy, so the linear Arrhenius plot with one single straight line and one breakpoint on it is too idealistic [95]. In most of the cases, the thermal effects over the threshold are non-reversible. Such an obvious case is the burning (temperature induced necrosis), which is sensed before it happens, the threshold for discomfort is $10-100$ times lower than a thermal dose for necrosis [96]. There is often not enough oxygen to accommodate the increased metabolic rate, resulting in hypoxia [97] and anaerobe metabolism, producing lactate [98] and cell destruction by acidosis. As a consequence, the concept of the irreversible phase-transition was developed and the treatment protocol became a step-down heating [99]. This method is supposed to have an irreversible phase transition at $42.5^{\circ} \mathrm{C}$, and after first overcoming this threshold, the treatment could be continued of a lower temperature, because the actual distortion (lowering the activation energy) is effective from that moment.

However, the definite phase-transition temperature (Arrhenius kink) changes by the chemotherapies [90], and it strongly depends on the heating dynamism (slow and rapid) [100] and on the pre-heating conditions as well. These facts predict a complex tissue dependent phase-transition (better to tell a chemical reaction); the drug metabolism and the transition dynamism are definitely involved.

The above described dose idea does not cover all cell-damage processes. $E_{a}$ could vary by the actual effects, having not only a simple, immediate necrosis. In a simple case when the electromagnetic heating is applied, we may suppose a deviation of the effects on at least two different groups; the dominant thermal changes, which depend only on the absorbed energy (SAR) irrespective the source of the energy delivery. Another part of the effect could depend on the mode of how the energy was delivered, that is, the actual electro-magnetic field, which is the source of the interactive forces, could make special effects on the ionic charges and dipoles which are the constructive elements of the biomatter. These effects are thermally induced, but not necessarily thermal. They are behaving at least as phase-transition of first order, having so called "latent heat". This means that after reaching the transition temperature that value does not change until the transition process is completed. In this interval the temperature will be independent from the pumped in SAR value. In this simplest case, when we divide the cause of the cell-death on the purely thermal and non-thermal but thermally induced components, the parallel reactions could be described as follows

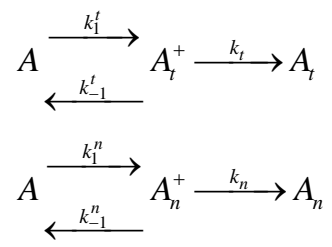

where $A$ is the cell treated complexly, and $A_{i}^{+},(i=t, n)$ are their activated (transition) state, the purely thermal component noted by subscript " $"$ ", while the "non-thermal" with " $n$ ", $A_{i},(i=t, n)$ is the death state of the cell. The $k_{1}^{i},(i=t, n)$ is the transition-rate to the active state, while $k_{-1}^{i},(i=t, n)$ is transition-rate to the repaired state, and $k_{i},(i=t, n)$ is the transition-rate to death.

Note the "non-thermal" component is only apparently not thermal. It well depend on the heat-energy which is needed for the chemical changes. This "latent heat" is energy associated with the energy of phase-change of the substance and it occurs in case of every first-order phase-transition. In case of pure water the latent-heat at melting of ice is $334 \mathrm{~kJ} / \mathrm{kg}$, while at the evaporation it is $2260 \mathrm{~kJ} / \mathrm{kg}$ at $0^{\circ} \mathrm{C}$ and $100^{\circ} \mathrm{C}$ respectively. During of the absorbing of the "latent heat" the temperature does not change, so it is better to use the statement of "actually non-temperature dependent" [95] instead of the "non-thermal", because during the absorbance process the temperature remains constant. Anyway, all the "non-thermal" components have definite energy-exchange which is thermal in the general meaning of thermodynamics.

Here, the dynamism of the processes is not included, and the time of staying in the actual state has no role. 
What is probable, however, is that the electric excitation process definitely has a longer time than the thermal one. The cross-effects are also not counted. The processes when one kind of excitation promotes the other one are calculated only by their final death independently from the history of the process itself. We consider that the thermal effects are dominantly necrotic, while the electrical one is dominantly necrotic, and note again that no strict border exists between the processes, or between the thermal and electric excitation. There is a massive appearance of thermally induced electric and electrically induced thermal effects, making the complete process complex. Applying a model of first order parallel reactions, the reaction-kinetic equations are

$$
\begin{aligned}
& \frac{\mathrm{d}[A]}{\mathrm{d} t}=-k_{1}^{n}[A]+k_{-1}^{n}\left[A_{n}^{+}\right] \\
& \frac{\mathrm{d}\left[A_{n}^{+}\right]}{\mathrm{d} t}=k_{1}^{n}[A]-k_{-1}^{n}\left[A_{n}^{+}\right]-k_{n}\left[A_{n}^{+}\right]
\end{aligned}
$$

Supposing the likely conditions of $k_{n} \ll k_{1}^{n}$, and then the $\left[A_{n}^{+}\right]$is probably stationer, so we get

$$
\frac{\mathrm{d}\left[A_{n}^{+}\right]}{\mathrm{d} t}=k_{1}^{n}[A]-k_{-1}^{n}\left[A_{n}^{+}\right]-k_{n}\left[A_{n}^{+}\right]=0
$$

From this, the concentration of the cells in activated state is

$$
\left[A_{n}^{+}\right]=\frac{k_{1}^{n}}{k_{-1}^{n}+k_{n}}[A]
$$

With this, we get the following simple reaction-kinetic equation

$$
\frac{\mathrm{d}[A]}{\mathrm{d} t}=-\frac{k_{n} k_{1}^{n}}{k_{-1}^{n}+k_{n}}[A]
$$

Following this method, the second reaction of Equation (21) will be such a simple decay reaction equation

$$
\frac{\mathrm{d}[A]}{\mathrm{d} t}=-\frac{k_{t} k_{1}^{t}}{k_{-1}^{t}+k_{t}}[A]
$$

After these calculations the cell damage could be described by the following irreversible parallel reaction scheme

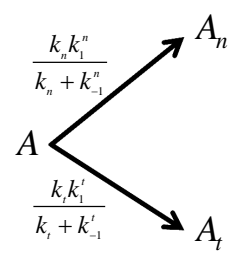

which could be described by the following reaction-kinetic equations

$$
\begin{aligned}
& -\frac{\mathrm{d}[A]}{\mathrm{d} t}=K_{n}[A]+K_{t}[A] \\
& \frac{\mathrm{d}\left[A_{n}\right]}{\mathrm{d} t}=K_{n}[A] \\
& \frac{\mathrm{d}\left[A_{t}\right]}{\mathrm{d} t}=K_{t}[A] \\
& K_{n}=\frac{k_{n} k_{1}^{n}}{k_{-1}^{n}+k_{n}}, \quad K_{t}=\frac{k_{t} k_{1}^{t}}{k_{-1}^{t}+k_{t}}
\end{aligned}
$$

where $K_{n}, K_{t}$ would be the "apparent" reaction rates. Supposing the $\left[A_{n}\right]_{0}=\left[A_{t}\right]_{0}=0$ initial conditions, we get the solution 


$$
\begin{aligned}
& {[A]=[A]_{0} \mathrm{e}^{-\left(K_{n}+K_{t}\right) t}} \\
& {\left[A_{n}\right]=\frac{K_{n}[A]_{0}}{K_{n}+K_{t}}\left[1-\mathrm{e}^{-\left(K_{n}+K_{t}\right) t}\right]} \\
& {\left[A_{t}\right]=\frac{K_{t}[A]_{0}}{K_{n}+K_{t}}\left[1-\mathrm{e}^{-\left(K_{n}+K_{t}\right) t}\right]}
\end{aligned}
$$

From where the so-called "branching ratio" is

$$
\frac{\left[A_{t}\right]}{\left[A_{n}\right]}=\frac{K_{t}}{K_{n}}
$$

This means that the concentration ratio of the death-cells depends only on the ratio of the apparent reaction rates. When the $\frac{K_{t}}{K_{n}}$ does not depend on the temperature, then the concentration ratio in the parallel reaction branches is constant, which means in our case that the ration of necrotic (caused by global SAR) and apoptotic cell damage (caused by local SAR) is independent of the temperature. We suppose that the apparent reaction rate also fulfils the Arrhenius law, then

$$
K_{i}=C_{i} \mathrm{e}^{-\frac{E_{a i}}{R_{G} T}}, \quad(i=e, t)
$$

where $C_{i}$ is a constant, $E_{a i}$ is the cellular activation energy of $i$-th components, and $R$ is the universal gas-constant $(R=8.314 \mathrm{~J} / \mathrm{K} / \mathrm{mole})$. Then the consequence is a fixed ratio

$$
\frac{K_{t}}{K_{n}}=\frac{C_{t}}{C_{n}}
$$

Consequently, the global cell damage described by the first equation of Equation (28) has the following kinetic equation

$$
-\frac{\mathrm{d}[A]}{\mathrm{d} t}=C_{t} \mathrm{e}^{-\frac{E_{a}}{R_{G} T}}\left(1+\frac{C_{n}}{C_{t}}\right)[A]=C_{t} \mathrm{e}^{-\frac{E_{a}}{R_{G} T}}\left(1+\frac{\left[A_{n}\right]}{\left[A_{t}\right]}\right)[A]
$$

where we used the branching ratio from Equation (30). Introducing the damage function as

$$
\Omega(t)=\ln \left(\frac{[A]\left(t_{0}\right)}{[A](t)}\right)
$$

where $t_{0}$ is the starting time of the process $\left(t_{0}=0\right)$ and the a consequence of Equation (33) we get

$$
\frac{\mathrm{d} \Omega(t)}{\mathrm{d} t}=C_{t} \mathrm{e}^{-\frac{E_{a}}{R_{G} T}}\left(1+\frac{\left[A_{n}\right]}{\left[A_{t}\right]}\right)
$$

With this, the damage function is calculable

$$
\begin{aligned}
& \Omega(t)=\left(1+\frac{\left[A_{n}\right]}{\left[A_{t}\right]}\right)_{0}^{t} \int_{t} \mathrm{e}^{-\frac{E_{a}}{R_{G} T(\tau)}} \mathrm{d} \tau=\Omega_{n}(t)+\Omega_{t}(t) \\
& \Omega_{t}(t)=\int_{0}^{t} C_{t} \mathrm{e}^{-\frac{E_{a}}{R_{G} T(\tau)}} \mathrm{d} \tau, \quad \Omega_{n}(t)=\frac{\left[A_{n}\right]}{\left[A_{t}\right]} \int_{0}^{t} C_{n} \mathrm{e}^{-\frac{E_{a}}{R_{G} T(\tau)}} \mathrm{d} \tau
\end{aligned}
$$

where $\Omega_{t}(t)$ is the thermal damage, and $\Omega_{n}(t)$ is the "non-thermal" (but anyway thermally induced) damage function. Consequently, the resultant damage function by means of the branching ratio could be expressed by the thermal damage function 


$$
\Omega(t)=\Omega_{n}(t)+\Omega_{t}(t)=\Omega_{t}(t)\left(1+\frac{\left[A_{n}\right]}{\left[A_{t}\right]}\right)
$$

On the above basis we introduce the generalized iso-effect of the thermal dose. Treatments could be compared by their efficacy, which has not only thermal, but "non-thermal” components, too. In this case

$$
\begin{aligned}
& \Omega\left(t_{1}, T_{1}\right)=\left(1+\frac{\left[A_{n}\right]}{\left[A_{t}\right]}\right) C_{t} \mathrm{e}^{-\frac{E_{a}}{R_{G} T_{1}}} t_{1}=\frac{t_{1}}{\Theta\left(T_{1}\right)} \\
& \Omega\left(t_{2}, T_{2}\right)=\left(1+\frac{\left[A_{n}\right]}{\left[A_{t}\right]}\right) C_{t} \mathrm{e}^{-\frac{E_{a}}{R_{G} T_{2}}} t_{2}=\frac{t_{2}}{\Theta\left(T_{2}\right)}
\end{aligned}
$$

where the situation corresponds to the pure thermal case described in Equations (12) and (13) if the points of 1 and 2 are close to each other, and the coefficients of the exponential function are nearly equal. Consequently, the isodose principle is identical with thermal despite of the additional (synergistic) effect of thermally induced, but not directly temperature dependent factors.

According to Equation (38) and using the condition of the equivalence described above, the functions of thermal damage at $T-t$ pair of values compared to a reference pair $T_{r}-t_{r}$ are

$$
\frac{t}{\Theta(T)}=\left(1+\frac{\left[A_{n}\right]}{\left[A_{r}\right]}\right) \frac{t_{r}}{\Theta\left(T_{r}\right)} \rightarrow t=t_{r}\left(1+\frac{\left[A_{n}\right]}{\left[A_{r}\right]}\right) \frac{\Theta(T)}{\Theta\left(T_{r}\right)}
$$

In a cumulative approach, we get, similarly to Equation (18)

$$
\mathrm{CEM}_{\text {gen }}=\int_{0}^{t}\left(1+\frac{\left[A_{n}\right]}{\left[A_{r}\right]}\right) \Psi^{T-T_{r}} \mathrm{~d} \tau
$$

where $\Psi$ is a function determined by the Arrhenius law

$$
\Psi \cong \mathrm{e}^{-\frac{E_{a}}{R_{G} T_{r}^{2}}}
$$

When $E_{a}$ and $A_{n}$ are constants and the $\Delta T=T-T_{r}$ difference is not too large, then

$$
\mathrm{CEM}_{\text {gen }} \approx Q_{\text {gen }} \int_{0}^{t} \Psi^{\frac{\Delta T(\tau)}{T_{r}}} \mathrm{~d} \tau
$$

where, $Q_{\text {gen }}$ is a generalized pre-factor

$$
Q_{\text {gen }}=t_{r}\left(1+\frac{\left[A_{n}\right]}{\left[A_{r}\right]}\right) \Psi^{T_{r}}
$$

The general equivalent time $\mathrm{CEM}_{\mathrm{gen}}$ in Equation (40) does not fix the reference for one definite cell-death or for definite duration of the process. The $A_{n} / A_{r}$ ratio could be very high in special processes (like electroporation [101] $A_{n} / A_{r} \approx 77$ ). The cell-destroying process could be guided by very little temperature change with extra huge thermal gradient on the plasma-membrane [102], which simply describes the full process "non-thermal". These effects are mostly induced by the frequency-dependent non-homogeneities in the distribution of induced and absorbed RF E-field and specific absorption rate at cellular level [2].

\section{Modulated Electro-Hyperthermia (Oncothermia)}

Modulated electro-hyperthermia (oncothermia, OTM) is devoted to solve the currentproblems [95] [103]. Oncothermia is a thermal process [104]. It uses nanoparticles (natural nanoclusters) as energy absorbers. These naturally presented nanoparticles (membrane clusters, rafts [105]) are non-artificial, well-studied nanoclusters in the membranes of the cells. OTM selectively targets these nanoclusters [106]. The selection mechanism is based 
on multiple effects [107] that cause effective changes in the targeted cell and in its immediate vicinity [108]. The technical details are described elsewhere [14]. Their energy absorption induces heat in the membrane. The heatenergy spreads all over the tumor and heats it up in an effective and well oriented way. Various complex signal pathways of transduction networks of the selectively targeted malignant cells are excited by the heated rafts [109], including the massive $\mathrm{Ca}^{2+}$ influx into the cytoplasm.

The apoptotic damage usually takes a longer time to be performed. Its usual visibility takes at least $24 \mathrm{~h}$, and could not be globally considered as simple Arrhenius plot, because this process is much more complex by its chemical changes. The multiple processes that are needed for apoptosis [110] contain a cell shrinking, nucleus condensing (pyknosis, time: 4 - 8 h), blebs on plasma-membrane, nucleus fragmenting (karyorrhexis, time: 10 $24 \mathrm{~h}$ ), and the appearance of apoptotic bodies (phagocyte engulf apoptotic bodies, time: 48 - $72 \mathrm{~h}$ ). The phenomenon of "no return" is the release of Cytochrome C [111], which happens at least $4 \mathrm{~h}$ after the start of apoptosis with the help of outer signal pathway (oncothermia cell killing) [111]. We know it from the measurements, that the Arrhenius plot is linear (no kink) below $42^{\circ} \mathrm{C}$, so oncothermia has to use this line for dose. However, the Arrhenius curve is mostly measured in vitro, and the necrotic cell-death was considered as the dominant thermal effect. The Arrhenius plot for thermally activated non-necrotic cell-killing has to describe the thermal behavior of the "point of no return" where the process becomes irreversible and the cell is "committed to die" [111]. This is the BAX pore formation on mitochondria and the release of Cytochrome $\mathrm{C}$. We have to choose a parameter characterizing a process of the non-necrotic cell-killing.

In case of oncothermia the physical character of the action is the electric field. This applied field increases the temperature by:

- global absorption (general SAR), which is the overall absorbed energy of the target divided by its mass, which is selected by impedance differences between the target and the normal tissue [112] uses certain $\mathrm{Ca}^{2+}$ influx and thermolysis [111].

This is because the thermal activation of transient receptor potentials (TRPs) has a crucial role in the apoptotic cell-death, caused by modulated electric field [111]. However, we can assume that the synergy of the thermal and electric effect and the induced damage function is proportional with each other. This was experimentally proven at two temperature points $\left(38^{\circ} \mathrm{C}\right.$ and $\left.42^{\circ} \mathrm{C}\right)$ [113]. Unfortunately, the exact cell-destruction mechanisms are not known in both classical hyperthermia and oncothermia cases, but the possible proportion can lead us to the oncothermia dose.

In cases of the modulated electrohyperthermia studies, the concentrations of the dead cells by thermal damage is $\left[A_{t}\right]$, and the concentration of the dead cells made by electric damage is $\left[A_{e}\right]$, then the branching ratio by the experiments [112] is

$$
\frac{\left[A_{e}\right]}{\left[A_{t}\right]} \approx 2
$$

Using the Equations (37) and (44) we get

$$
\Omega(t)=3 \Omega_{t}(t)
$$

The combined thermal and electric effects have three times more cell distortion than the thermal has alone.

The selective and effective cell destruction makes a new kind of hyperthermia in oncology possible. This new treatment could use the definite electric and thermal in homogeneities of the tumor to kill effectively the cancer-cells without hurting their healthy vicinity. This selective SAR process causes the strong synergy between the direct thermal and indirect thermal (special electric field absorption) processes [113]. The thermal effect in this case is different than in the classical hyperthermia heating. In the conventional approach the goal is the homogeneous temperature all over the tumor, while according to the cellular selectivity, oncothermia is not based on the homogeneous heating. The specific absorption rate (SAR) is derived by the specialties of the cancer-cells allowing to find them, and absorbed the SAR in that place. Due to this process the prospects of oncothermia is huge even in those tumor cases, which are generally contraindicated for the overall heating of the mass; like brain, eye, or other sensitive organs or inoperable cases. These sensitive places are treated with success with oncothermia [95] [114] and even the bleeding tumors and the inflammatory cases can also be successfully treated with the method [115]. 


\section{Conclusion}

Generalized dose has been introduced for the non-homogeneous temperature distribution including the electric field absorption as a component of SAR. The generalization is discussed in the frame of thermal effects applied in the Arrhenius thermal law. The dosing and efficacy of modulated electro-hyperthermia (oncothermia) are described, and due to the non-homogeneous heating and selective targeting it is about three times higher than that of the homogeneous classical mass-heating.

\section{References}

[1] Seegenschmiedt, M.H. and Vernon, C.C. (1996) A Historical Perspective on Hyperthermia in Oncology. In: Seegenschmiedt, M.H., Fessenden, P. and Vernon, C.C., Eds., Thermo-Radiotherapy and Thermo-Chemiotherapy, Springer, Berlin Heidelberg, 3-46. http://dx.doi.org/10.1007/978-3-642-60938-1_1

[2] Roussakow, R. (2013) The History of Hyperthermia Rise and Decline. Conference Papers in Medicine, 2013, Article ID: 428027.

[3] Baronzio, G., Jackson, M., Lee, D. and Szasz, A. (2013) Editorial of the Conference of the International Clinical Hyperthermia Society 2012. Conference Papers in Medicine, 2013, Article ID: 690739.

[4] Szasz, A. (2013) “Quo Vadis” Oncologic Hyperthermia? Conference Papers in Medicine, 2013, Article ID: 201671.

[5] Jones, E., Thrall, D., Dewhirst, M.W. and Vujaskovic, Z. (2006) Prospective Thermal Dosimetry: The Key to Hyperthermia's Future. International Journal of Hyperthermia, 22, 247-253. http://dx.doi.org/10.1080/02656730600765072

[6] von Ardenne, A. and Wehner, H. (2005) Extreme Whole-Body Hyperthermia with Water-Filtered Infrared-A Radiation. Eurekah Bioscience Collection, Oncology, Landes Bioscience.

[7] Devrient, W. (1950) Überwärmungsbäder. Weber’s Verlag, Berlin.

[8] Fieber, H.F. (1957) Unspezifische Abwehrvorgänge, Unspezifische Therapie. Georg Thieme, Stuttgart.

[9] Lampert, H. (1948) Überwärmung als Heilmittel. Hippokrates, Stuttgart.

[10] Schmidt, K.L. (1987) Hyperthermie und Fieber. Hippokrates, Stuttgart.

[11] Heckel, M. (1990) Ganzkörperhyperthermie und Fiebertherapie—Grundlagen und Praxis. Hippokrates, Stuttgart.

[12] Heckel, M. (1992) Fiebertherapie und Ganzkörper-HT, Bessere Verträglichkeit und Effizienz durch thermoregulatorisch ausgewogene, kombinierte Anwendung beider Verfahren. ThermoMed, No. 14, 19 p.

[13] Hildebrandt, B., Drager, J., Kerner, T., Deja, M., Löffel, J., Stroszczynski, C., et al. (2004) Whole-Body Hyperthermia in the Scope of von Ardenne's Systemic Cancer Multistep Therapy (sCMT) Combined with Chemotherapy in Patients with Metastatic Colorectal Cancer: A Phase I/II Study. International Journal of Hyperthermia, 20, 317-333. http://dx.doi.org/10.1080/02656730310001637316

[14] Wust, P., Riess, H. and Hildebrandt, B. (2000) Feasibility and Analysis of Thermal Parameters for the Whole-Body Hyperthermia System IRATHERM. International Journal of Hyperthermia, 4, 325-339.

[15] Szasz, A., Szasz, O. and Szasz, N. (2006) Physical Background and Technical Realization of Hyperthermia. In: Baronzio, G.F. and Hager, E.D., Eds., Hyperthermia in Cancer Treatment: A Primer, Springer Science, Berlin, 27-59. http://dx.doi.org/10.1007/978-0-387-33441-7_3

[16] Nishide, O.J.R. (1985) The Role of Magnetic Inductiontechniques for Producing Hyperthermia. In: Anghileri, L.J., Robert, J., Eds., Hyperthermia in Cancer Treatment, Vol. II, CRC Press, Boca Roton, 141-154.

[17] Nishide, S.M. and Ueno, S. (1993) A Method of Localized Hyperthermia by Using a Figure-of-Eight Coil and ShortCircuit Rings. Proceedings of the 15th Annual International Conference of the IEEE Engineering in Medicine and Biology Society, San Diego, 31 October 1993, 1447-1448. http://dx.doi.org/10.1109/IEMBS.1993.979222

[18] Jojo, M., Murakami, A., Sato, F., Matsuki, H. and Sato, T. (2001) Consideration of Handy Excitation Apparatus for the Inductive Hyperthermia. IEEE Transactions on Magnetics, 37, 2944-2946. http://dx.doi.org/10.1109/20.951355

[19] Dahl, O., Dalene, R. and Schem, B.C. (1999) Status of Clinical Hyperthermia. Acta Oncologica, 38, 863-873. http://dx.doi.org/10.1080/028418699432554

[20] Senior, K. (2001) Hyperthermia and Hypoxia for Cancer-Cell Destruction. Lancet Oncology, 2, 524-525. http://dx.doi.org/10.1016/S1470-2045(01)00470-3

[21] Wust, P., Hildebrandt, B., Sreenivasa, G., Rau, B., Gellermann, J., Riess, H., et al. (2002) Hyperthermia in Combined Treatment of Cancer. Lancet Oncology, 3, 487-497. http://dx.doi.org/10.1016/S1470-2045(02)00818-5

[22] Szasz, A., Szasz, O. and Szasz, N. (2001) Electro-Hyperthermia: A New Paradigm in Cancer Therapy. Deutsche Zeitschrift für Onkologie, 33, 91-99. http://dx.doi.org/10.1055/s-2001-19447

[23] Szasz, A., Szasz, N. and Szasz, O. (2003) Hyperthermie in der Onkologie mit einem historischen Uberblick. Deutsche 
Zeitschrift für Onkologie, 35, 140-154. http://dx.doi.org/10.1055/s-2003-43178

[24] Abe, M., Hiraoka, M., Takahashi, M., Egawa, S., Matsuda, C., Onoyama, Y., et al. (1986) Multi-Institutional Studies on Hyperthermia Using an 8-MHz Radiofrequency Capacitive Heating Device (Thermotron RF-8) in Combination with Radiation for Cancer Therapy. Cancer, 58, 1589-1595. http://dx.doi.org/10.1002/1097-0142(19861015)58:8<1589::AID-CNCR2820580802>3.0.CO;2-B

[25] Nagy, G., Meggyeshazi, N. and Szasz, O. (2013) Deep Temperature Measurements in Oncothermia Processes. Conference Papers in Medicine, 2013, Article ID: 685264. http://dx.doi.org/10.1155/2013/685264

[26] Vargas, H.I., Dooley, W.C., Gardner, R.A., Gonzalez, K.D., Venegas, R., Heywang-Kobrunner, S.H. and Fenn, A.J. (2004) Focused Microwave Phased Array Thermotherapy for Ablation of Early-Stage Breast Cancer: Results of Thermal Dose Escalation. Annals of Surgical Oncology, 11, 139-146. http://dx.doi.org/10.1245/ASO.2004.03.059

[27] Ellis, L.M., Curley, S.A. and Tanabe, K.K. (2004) Radiofrequency Ablation of Cancer. Springer Verlag, New York, Berlin.

[28] Goldberg, S.N., Gazelle, G.S., Solbiati, L., Livraghi, T., Tanabe, K.K., Hahn, P.F. and Mueller, P.R. (1998) Ablation of Liver Tumors Using Percutaneous RF Therapy. American Journal of Roentgenology, 170, 1023-1028. http://dx.doi.org/10.2214/ajr.170.4.9530053

[29] Okuma, T., Matsuoka, T., Yamamoto, A., Oyama, Y., Inoue, K., Nakmura, K. and Inoue, Y. (2007) Factors Contributing to Cavitation after CT-Guided Percutaneous Radiofrequency Ablation for Lung Tumors. Journal of Vascular and Interventional Radiology, 18, 399-404. http://dx.doi.org/10.1016/j.jvir.2007.01.004

[30] Chhajed, P.N. and Tamm, M. (2003) Radiofrequency Heat Ablation for Lung Tumors: Potential Applications. Medical Science Monitor, 9, ED5-7.

[31] Hall-Craggs, M.A. and Vaidya, J.S. (2002) Minimally Invasive Therapy for the Treatment of Breast Tumours. European Journal of Radiology, 42, 52-57. http://dx.doi.org/10.1016/S0720-048X(02)00019-0

[32] Seed, P.K. and Stea, B. (1996) Thermoradiotherapy for Brain Tumors. In: Seegenschmiedt, M.H., Fessenden, P. and Vernon, C.C., Eds., Thermoradiotherapy and Thermochemotherapy, Vol. 2, Clinical Applications, Springer Verlag, Telos, 159-173.

[33] Nakajima, T., Roberts, D.W., Ryan, T.P., Hoopes, P.J., Coughlin, C.T. and Trembly, S. (1993) Pattern of Response to Interstitial Hyperthermia and Brachytherapy for Malignant Intracranial Tumor: A CT Analysis. International Journal of Hyperthermia, 9, 491-502. http://dx.doi.org/10.3109/02656739309005047

[34] Iacono, R.P., Stea, B., Lulu, B.A., Celas, T. and Cassady, J.R. (1992) Template-Guided Stereotactic Implantation of Malignant Brain Tumors for Interstitial Thermoradiotherapy. Stereotactic and Functional Neurosurgery, 59, 199-204. http://dx.doi.org/10.1159/000098942

[35] Sneed, P.K., Gutin, P.H., Stauffer, P.R., Phillips, T.L., Prados, M.D., Weaver, K.A., et al. (1992) Thermoradiotherapy of Recurrent Malignant Brain Tumors. International Journal of Radiation Oncology, Biology, Physics, 23, 853-861. http://dx.doi.org/10.1016/0360-3016(92)90659-6

[36] Borok, T.L., Winter, A., Laing, J., Paglione, R., Sterzer, F., Sinclair, I. and Plafker, J. (1988) Microwave Hyperthermia Radiosensitized Iridium-192 for Recurrent Brain Malignancy. Medical Dosimetry, 13, 29-36. http://dx.doi.org/10.1016/S0958-3947(98)90109-1

[37] Moran, C.J., Marchosky, J.A., Wippold, F.J., DeFord, J.A. and Fearnot, N.E. (1995) Conductive Interstitial Hyperthermia in the Treatment of Intracranial Metastatic Disease. Journal of Neuro-Oncology, 26, 53-63. http://dx.doi.org/10.1007/BF01054769

[38] Fan, M., Ascher, P.W., Schröttner, O., Ebner, F., Germann, R.H. and Kleinert, R. (1992) Interstitial 1.06 Nd:YAG Laser Thermotherapy for Brain Tumors under Real-Time Monitoring of MRI: Experimental Study and Phase I Clinical Trial. Journal of Clinical Laser Medicine \& Surgery, 10, 355-361.

[39] Kahn, T., Harth, T., Bettag, M., Schwabe, B., Ulrich, F., Schwarzmaier, H.J. and Mödder, U. (1997) Preliminary Experience with the Application of Gadolinium-DTPA before MR Imaging-Guided Laser-Induced Interstitial Thermotherapy of Brain Tumors. Journal of Magnetic Resonance Imaging, 7, 226-229. http://dx.doi.org/10.1002/jmri.1880070135

[40] Ara, G., Anderson, R.R. and Mandel, K.G. (1989) Irradiation of Pigmented Melanoma Cells with High-Intensity Pulsed Radiation Generates Acoustic Waves and Kills the Cells. Lasers in Surgery and Medicine, 10, 52-59. http://dx.doi.org/10.1002/lsm.1900100112

[41] Walser, E.M. (2005) Percutaneous Laser Ablation in the Treatment of Hepatocellular Carcinoma with a Tumor Size of $4 \mathrm{~cm}$ or Smaller. Journal of Vascular and Interventional Radiology, 16, 1427-1429. http://dx.doi.org/10.1097/01.RVI.0000188755.61481.E8

[42] Pacella, C.M., Valle, D., Bizzarri, G., Pacella, S., Brunetti, M., Maritati, R., et al. (2006) Percutaneous Laser Ablation in Patients with Isolated Unresectable Live Metastases from Colorectal Cancer: Results of a Phase II Study. Acta On- 
cologica, 45, 77-83. http://dx.doi.org/10.1080/02841860500438029

[43] Wang, Y., Gonzalez, M., Cheng, C., Haouala, A., Krueger, T., Peters, S., et al. (2012) Photodynamic Induced Uptake of Liposomal Doxorubicin to Rat Lung Tumors Parallels Tumor Vascular Density. Lasers in Surgery and Medicine, 44, 318-324. http://dx.doi.org/10.1002/lsm.22013

[44] Levy, J.G. (1994) Photosensitizers in Photodynamic Therapy. Seminars in Oncology, 21, 4-10.

[45] Torchilin, V.P. (2006) Multifunctional Nanocarriers. Advanced Drug Delivery Reviews, 58, 1532-1555. http://dx.doi.org/10.1016/j.addr.2006.09.009

[46] Brannon-Peppas, L. and Blanchette, J.O. (2004) Nanoparticle and Targeted Systems for Cancer Therapy. Advanced Drug Delivery Reviews, 56, 1649-1659. http://dx.doi.org/10.1016/j.addr.2004.02.014

[47] Chatterjee, D.K., Fong, L.S. and Zhang, Y. (2008) Nanoparticles in Photodynamic Therapy: An Emerging Paradigm. Advanced Drug Delivery Reviews, 60, 1627-1637. http://dx.doi.org/10.1016/j.addr.2008.08.003

[48] Choi, J., Yang, J., Bang, D., Park, J., Suh, J.S., Huh, Y.M. and Haam, S. (2012) Targetable Gold Nanorods for Epithelial Cancer Therapy Guided by Near-IR Absorption Imaging. Small, 8, 746-753. http://dx.doi.org/10.1002/smll.201101789

[49] Jain, P.K., Huang, X., El-Sayed, I.H. and El-Sayed, M.A. (2008) Noble Metals on the Nanoscale: Optical and Photothermal Properties and Some Applications in Imaging, Sensing, Biology, and Medicine. Accounts of Chemical Research, 41, 1578-1586. http://dx.doi.org/10.1021/ar7002804

[50] Rand, R.W., Snow, H.D. and Brown, W.J. (1982) Thermomagnetic Surgery for Cancer. Journal of Surgical Research, 33, 177-183. http://dx.doi.org/10.1016/0022-4804(82)90026-9

[51] Matsuki, H., Satoh, T. and Murakami, K. (1990) Local Hyperthermia Based on Soft Heating Method Utilizing Temperature Sensitive Ferrite-Rod. IEEE Transactions on Magnetics, 26, 1551-1553. http://dx.doi.org/10.1109/20.104442

[52] Gilchrist, R.K., Medal, R., Shorey, W.D., Hanselman, R.C., Parrott, J.C. and Taylor, C.B. (1957) Selective Inductive Heating of Lymph Nodes. Annals of Surgery, 146, 596-606. http://dx.doi.org/10.1097/00000658-195710000-00007

[53] Jordan, A., Scholz, R., Wust, P., Faehling, H. and Felix, R. (1999) Magnetic Fluid Hyperthermia (MFH): Caner Treatment with AC Magnetic Field Induced Excitation of Biocompatible Supermegnetic Nanoparticles. Journal of Magnetism and Magnetic Materials, 201, 413-419. http://dx.doi.org/10.1016/S0304-8853(99)00088-8

[54] Bakht, M.K., Sadeghi, M., Pourbaghi-Masouleh, M. and Tenreiro, C. (2012) Scope of Nanotechnology-Based Radiation Therapy and Thermotherapy Methods in Cancer Treatment. Current Cancer Drug Targets, 12, 998-1015. http://dx.doi.org/10.2174/156800912803251216

[55] Jordan, A., Scholz, R., Maier-Hauff, K., Johannsen, M., Wust, P., Nadobny, J., et al. (2001) Presentation of a New Magnetic Field Therapy System for the Treatment of Human Solid Tumors with Magnetic Fluid Hyperthermia. Journal of Magnetism and Magnetic Materials, 225, 118-126. http://dx.doi.org/10.1016/S0304-8853(00)01239-7

[56] Sperling, R.A., Gil, P.R., Zhang, F., Zanella, M. and Parak, W.J. (2008) Biological Applications of Gold Nanoparticles. Chemical Society Reviews, 37, 1896-1908. http://dx.doi.org/10.1039/b712170a

[57] Secret, E., Smith, K., Dubljevic, V., Moore, E., Macardle, P., Delalat, B., et al. (2013) Antibody Porous Silicon Nanoparticles for Vectorization of Hydrophobic Drugs. Advanced Healthcare Materials, 40, 718-727. http://dx.doi.org/10.1002/adhm.201200335

[58] Gordon, R.T., Hines, J.R. and Gordon, D. (1979) Intracellular Hyperthermia: A Biophysical Approach to Cancer Treatment via Intracellular Temperature and Biophysical Alteration. Medical Hypotheses, 5, 83-102. http://dx.doi.org/10.1016/0306-9877(79)90063-X

[59] Rabin, Y. (2002) Is Intracellular Hyperthermia Superior to Extracellular in the Thermal Sense? International Journal of Hyperthermia, 18, 194-202. http://dx.doi.org/10.1080/02656730110116713

[60] Andocs, G., Meggyeshazi, N., Balogh, L., Spisak, S., Maros, M.E., Balla, P., et al. (2015) Upregulation of Heat Shock Proteins and the Promotion of Damage Associated Molecular Pattern Signals in a Colorectal Cancer Model by Modulated Electrohyperthermia. Cell Stress and Chaperons, 20, 37-46. http://dx.doi.org/10.1007/s12192-014-0523-6

[61] Keisari, Y. (2013) Tumor Ablation, Effects on Systemic and Local Anti-Tumor Immunity and on Other Tumor-Microenvironment Interactions. The Tumor Microenvironment, Vol. 5, Springer, Dordrecht.

[62] Schroeder, A., Heller, D.A., Winslow, M.M., Dahlman, J.E., Pratt, G.W., Langer, R., et al. (2012) Treating Metastatic Cancer with Nanotechnology. Nature Reviews Cancer, 12, 39-50. http://dx.doi.org/10.1038/nrc3180

[63] Qin, W., Akutsu, Y., Andocs, G., Suganami, A., Hu, X., Yusup, G., et al. (2014) Modulated Electro-Hyperthermia Enhances Dendritic Cell Therapy through an Abscopal Effect in Mice. Oncology Reports, 32, 2373-2379. http://dx.doi.org/10.3892/or.2014.3500

[64] Andocs, G., Meggyeshazi, N., Okamoto, Y., Balogh, L. and Szasz, O. (2013) Bystander Effect of Oncothermia. Conference Papers in Medicine, 2013, Article ID: 953482. http://dx.doi.org/10.1155/2013/953482 
[65] Meggyesházi, N., Andocs, G., Balogh, L., Balla, P., Kiszner, G., Teleki, I., et al. (2014) DNA Fragmentation and Caspase-Independent Programmed Cell Death by Modulated Electrohyperthermia. Strahlentherapie und Onkologie, 10, 815-822. http://dx.doi.org/10.1007/s00066-014-0617-1

[66] Immunotherm (2014) Registered Trademark of Oncotherm Kft. Ref. No. 012226585.

[67] Szasz, A. and Vincze, G. (2006) Dose Concept of Oncological Hyperthermia: Heat-Equation Considering the Cell Destruction. Journal of Cancer Research and Therapeutics, 2, 171-181. http://dx.doi.org/10.4103/0973-1482.29827

[68] Szasz, A. (2007) Hyperthermia, a Modality in the Wings. Journal of Cancer Research and Therapeutics, 3, 56-66. http://dx.doi.org/10.4103/0973-1482.31976

[69] LeVeen, H.H., Wapnick, S., Picone, V., Folk, G. and Ahmed, N. (1976) Tumor Eradication by Radiofrequency Therapy. JAMA, 235, 2198-2200. http://dx.doi.org/10.1001/jama.1976.03260460018014

[70] Pettigrew, R.T., Gait, J.M., Ludgate, C.M. and Smith, A.N. (1974) Clinical Effects of Whole-Body Hyperthermia in Advanced Malignancy. BMJ, 4, 679-682. http://dx.doi.org/10.1136/bmj.4.5946.679

[71] Johnson, H.J. (1940) The Action of Short Radio Waves on Tissues III. A Comparison of the Thermal Sensitivities of Transplantable Tumors "in Vivo" and “in Vitro". American Journal of Cancer, 38, 533-550.

[72] Linkermann, A. and Green, D.R. (2014) Necroptosis. The New England Journal of Medicine, 370, 455-465. http://dx.doi.org/10.1056/NEJMra1310050

[73] Berghe, T.V., Linkermann, A., Jouan-Lanhouet, S., Walczak, H. and Vandenabeele, P. (2014) Regulated Necrosis: The Expanding Network of Non-Apoptotic Cell Death Pathways. Nature Reviews Molecular Cell Biology, 15, 135-147. http://dx.doi.org/10.1038/nrm3737

[74] van der Zee, J. (2005) Presentation on Conference in Mumbai. India. http://www.google.com/\#sclient=psy\&hl=en\&site=\&source=hp\&q=\%22van+der+Zee\%22+Mumbai+ext:ppt\&btnG=G oogle + Search \&aq $=\& a q i=\& a q l=\& o q=\& p b x=1 \& b a v=$ on

[75] Findlay, R.P. and Dimbylow, P.J. (2005) Effects of Posture on FDTD Calculations of Specific Absorption Rate in a Voxel Model of the Human Body. Physics in Medicine and Biology, 50, 3825-3835. http://dx.doi.org/10.1088/0031-9155/50/16/011

[76] Joo, E., Szasz, A. and Szendro, P. (2005) Metal-Framed Spectacles and Implants and Specific Absorption Rate among Adults and Children Using Mobile Phones at 900/1800/2100 MHz. Electromagnetic Biology and Medicine, 25, 103112. http://dx.doi.org/10.1080/15368370600719042

[77] Wang, J.Q., Mukaide, N. and Fujiwara, O. (2003) FTDT Calculation of Organ Resonance Characteristics in an Anatomically Based Human Model for Plane-Wave Exposure. Proceedings of Asia-Pacific Conference on Environmental Electromagnetics, Hangzhou, 4-7 November, 126-129.

[78] Armstron Laboratory (1997) Radiofrequency Radiation Dosimetry Handbook. USAF School of Aerospace Medicine, AFSC, Brooks Air Force Base. http://niremf.ifac.cnr.it/docs/HANDBOOK/chp1.htm

[79] Gillooly, J.F., Allen, A.P., Savage, V.M., Charnov, E.L., West, G.B. and Brown, J.H. (2006) Response to Clarke and Fraser: Effects to Temperature on Metabolic Rate. Functional Ecology, 20, 400-404. http://dx.doi.org/10.1111/j.1365-2435.2006.01110.x

[80] Lindholm, C.-E. (1992) Hyperthermia and Radiotherapy. PhD Thesis, Lund University, Malmo.

[81] Hafstrom, L., Rudenstam, C.M., Blomquist, E., Ingvar, C., Jönsson, P.E., Lagerlöf, B., et al. (1991) Regional Hyperthermic Perfusion with Melphalan after Surgery for Recurrent Malignant Melanoma of the Extremities. Journal of Clinical Oncology, 9, 2091-2094.

[82] Chang, I.A. (2010) Considerations for Thermal Injury Analysis for RF Ablation Devices. The Open Biomedical Engineering Journal, 4, 3-12. http://dx.doi.org/10.2174/1874120701004010003

[83] Dewey, W.C., Hopwood, L.E., Sapareto, S.A. and Gerweck, L.E. (1977) Cellular Responses to Combinations of Hyperthermia and Radiation. Radiology, 123, 463-474. http://dx.doi.org/10.1148/123.2.463

[84] Pearce, J.A. (2012) Thermal Dose Models: Irreversible Alterations in Tissues. In: Moros, E.G., Ed., Physics of Thermal Therapy. Fundamentals and Clinical Applications, Taylor and Francis, CRC Press, Boca Raton, 23-40.

[85] Wright, N.T. (2001) On a Relationship between the Arrhenius Parameters from Thermal Damage Studies. Journal of Biomechanical Engineering, 125, 300-304. http://dx.doi.org/10.1115/1.1553974

[86] Sapareto, S.A. and Dewey, W.C. (1984) Thermal Dose Determination in Cancer Therapy. International Journal of Radiation Oncology, Biology, Physics, 10, 787-800. http://dx.doi.org/10.1016/0360-3016(84)90379-1

[87] Pearce, J.A. (2009) Relationship between Arrhenius Models of Thermal Damage and the CEM 43 Thermal Dose. Proceedings of SPIE, Energy-Based Treatment of Tissue and Assessment V, 7181, Article ID: 718104.

http://dx.doi.org/10.1117/12.807999 
[88] Urano, M. and Douple, E. (1994) Hyperthermia in Oncology. Vol. 4, Chemopotentiation by Hyperthermia, VSP Utrecht, Tokyo, 173.

[89] Dewey, W.C. (1994) Arrhenius Relationships from the Molecule and Cell to the Clinic. International Journal of Hyperthermia, 10, 457-483. http://dx.doi.org/10.3109/02656739409009351

[90] Urano, M. (1994) Thermochemotherapy: From in Vitro and in Vivo Experiments to Potential Clinical Application. In: Urano, M. and Douple, E., Eds., Hyperthermia and Oncology, Vol. 4, VSP Utrecht, Tokyo, 169-204.

[91] Erdmann, B., Lang, J. and Seebass, M. (1998) Optimization of Temperature Distributions for Regional Hyperthermia Based on a Nonlinear Heat Transfer Model. Annals of the New York Academy of Sciences, 858, 36-46.

[92] Lindholm, C.-E. (1992) Hyperthermia and Radiotherapy. PhD Thesis, Lund University, Malmo.

[93] Henriques, F.C. and Moritz, A.R. (1947) Studies of Thermal Injury I: The Conduction of Heat to and through Skin and the Temperature Attained Therein. American Journal of Pathology, 23, 530-549.

[94] Watanabe, M., Suzuki, K., Kodama, S. and Sugahara, T. (1995) Normal Human Cells at Confluence Get Heat Resistance by Efficient Accumulation of HSP72 in Nucleus. Carcinogenesis, 16, 2373-2380. http://dx.doi.org/10.1093/carcin/16.10.2373

[95] Szasz, A., Szasz, N. and Szasz, O. (2010) Oncothermia-Principles and Practices. Springer, Heidelberg.

[96] Silbernagl, S. and Despopoulos, A. (2012) Taxchenatlas Physiologie. Thieme-Verlag, Stuttgart.

[97] Dewhirst, M.W., Ozimek, E.J., Gross, J. and Cetas, T.C. (1980) Will Hyperthermia Conquer the Elusive Hypoxic Cell? Radiology, 137, 811-817. http://dx.doi.org/10.1148/radiology.137.3.7003650

[98] Vaupel, P.W. and Kelleher, D.K. (1996) Metabolic Status and Reaction to Heat of Normal and Tumor Tissue. In: Seegenschmiedt, M.H., Fessenden, P. and Vernon, C.C. Eds., Thermo-Radiotherapy and Thermo-Chemiotherapy, Vol. 1, Biology, Physiology and Physics, Springer Verlag, Berlin, 157-176.

[99] Lindegaard, J.C. (1992) Thermosensitization Induced by Step-Down Heating. International Journal of Hyperthermia, 8, 561-582. http://dx.doi.org/10.3109/02656739209037994

[100] Hayashi, S., Kano, E., Hatashita, M., Othsubo, T., Katayama, K. and Matsumoto, H. (2001) Fundamental Aspects of Hyperthermia on Cellular and Molecular Level. In: Kosaka, M., Sugahara, T., Schmidt, K.L. and Simon, E., Eds., Thermotherapy for Neoplasia, Inflammation, and Pain, Springer, Tokyo, 335-345. http://dx.doi.org/10.1007/978-4-431-67035-3_38

[101] Weaver, J.C. and Chizmadzhev, Y.A. (1996) Theory of Electroporation: A Review. Bioelectrochemistry and Bioenergetics, 41, 135-160. http://dx.doi.org/10.1016/S0302-4598(96)05062-3

[102] Garner, A.L., Deminsky, M., Necuales, V.B., Chashihin, V., Knizhnik, A. and Poatpkin, B. (2013) Cell Membrane Thermal Gradients Induced by Electromagnetic Fields. Journal of Applied Physics, 113, Article ID: 214701. http://dx.doi.org/10.1063/1.4809642

[103] Szasz, A. and Morita, T. (2012) Heat Therapy in Oncology-Oncothermia, New Paradigm in Hyperthermia. Nippon Hyoronsha, Tokyo.

[104] Baronzio, G., Parmar, G., Ballerini, M., Szasz, A., Baronzio, M. and Cassutti, V. (2014) A Brief Overview of Hyperthermia in Cancer Treatment. Journal of Integrative Oncology, 3, 115. http://dx.doi.org/10.4172/2329-6771.1000115

[105] Rajendran, L. and Simons, K. (2005) Lipid Rafts and Membrane Dynamics. Journal of Cell Science, 118, $1099-1102$. http://dx.doi.org/10.1242/jcs.01681

[106] Szasz, O. and Szasz, A. (2014) Oncothermia—Nano-Heating Paradigm. Journal of Cancer Science \& Therapy, 6, 117121. http://dx.doi.org/10.4172/1948-5956.1000259

[107] Szasz, A., Iluri, N. and Szasz, O. (2013) Local Hyperthermia in Oncology-To Choose or not to Choose? In: Huilgol, N., Ed., Hyperthermia, InTech, Winchester, 1-82.

[108] Szasz, A., Vincze, G., Szasz, O. and Szasz, N. (2003) An Energy Analysis of Extracellular Hyperthermia. Electromagnetic Biology and Medicine, 22, 103-115. http://dx.doi.org/10.1081/JBC-120024620

[109] Szasz, A. (2013) Challenges and Solutions in Oncological Hyperthermia. Thermal Medicine, 29, 1-23. http://dx.doi.org/10.3191/thermalmed.29.1

[110] Elmore, S. (2007) Apoptosis: A Review of Programmed Cell Death. Toxicologic Pathology, 35, 495-516. http://dx.doi.org/10.1080/01926230701320337

[111] Chang, L.K., Putcha, G.V., Deshmukh, M. and Johnson Jr., E.M. (2002) Mitochondrial Involvement in the Point of No Return in Neuronal Apoptosis. Biochimie, 84, 223-231. http://dx.doi.org/10.1016/S0300-9084(02)01372-X

[112] Szasz, A. (2014) Bioelectromagnetic Paradigm of Cancer Treatment-Oncothermia. In: Rosch, P.J., Ed., Bioelectromagnetic and Subtle Energy Medicine, Taylor and Francis Group, CRC Press, Boca Raton, 323-336.

[113] Andocs, G., Renner, H., Balogh, L., Fonyad, L., Jakab, C. and Szasz, A. (2009) Strong Synergy of Heat and Modulated 
Electromagnetic Field in Tumor Cell Killing. Study of HT29 Xenograft Tumors in a Nude Mice Model. Strahlentherapie und Onkologie, 185, 120-126. http://dx.doi.org/10.1007/s00066-009-1903-1

[114] Wismeth, C., Dudel, C., Pascher, C., Ramm, P., Pietsch, T., Hirschmann, B., et al. (2010) Transcarnial ElectroHyperthermia Combined with Alkylating Chemotherapy in Patients with Relapsed High-Grade Gliomas-Phase I Clinical Results. Journal of Neuro-Oncology, 98, 395-405. http://dx.doi.org/10.1007/s11060-009-0093-0

[115] Jeung, T.S., Ma, S.Y., Yu, J. and Lim, S. (2013) Cases That Respond to Oncothermia Monotherapy. Conference Papers in Medicine, 2013, Article ID: 392480. http://dx.doi.org/10.1155/2013/392480 